\title{
Ecological function regionalization of fluvial corridor landscapes and measures for ecological regeneration in the middle and lower reaches of the Tarim River, Xinjiang of China
}

\author{
HuaRong $\mathrm{ZHOU}^{1 *}$, DuNing XIAO ${ }^{2}$ \\ ${ }^{1}$ Xinjiang Institute of Ecology and Geography, Chinese Academy of Sciences, Urumqi 830011, China; \\ ${ }^{2}$ Shenyang Institute of Applied Ecology, Chinese Academy of Sciences, Shenyang 100016, China
}

\begin{abstract}
The middle and lower reaches of the Tarim River are currently one of the main regions of ecological restoration in the arid areas of western China. Using the principles and method of landscape ecology, this study has chosen the fluvial corridor landscape in the middle and lower reaches of the Tarim River, and discusses the region's ecologically functional regionalization system and issues related to its practical classification. On this basis the corresponding regionalizing principles and standards were developed which were used to qualitatively divide the three main landscapes as the ecologically functional areas in the drainage basin. The paper has also analyzed the characteristic of the study areas, and has put forward the measures for its ecological restoration.
\end{abstract}

Keywords: fluvial corridor landscape; ecological function regionalization; ecological regeneration; Tarim River

\section{Introduction}

Ecosystem is a united integration forming in a continuous matter cycle and energy flow between all the living things (i.e. the communities of living things) inhabiting together in certain space and environment (Li, 2000). Ecological function of ecosystem can be classified into three main types, i.e. the biological production, environmental service and cultural support (Wang, 1995; Wang, 1996; Wang and Han, 1998), which is the basis for human beings existence and development of the modern civilization.

Landscape is a heterogeneous continental region composed of repetitive and inter-linked ecosystems, either in group or similar mode running from a few kilometers to several hundred kilometers. Though different for a region, such integration contains similar ecological characeistics (Fu et al., 2003; Xiao et al., 2003). Division of the functional areas is based on the spatial structure of landscapes, which is related to the spatial patterns of landscapes in the peripheral regions. The purposes are to satisfy three main basic functions: the environmental services, biological production and cultural support to the landscape ecosystems through forming the rational spatial patterns of landscapes in a planned area, improving the environment conditions, promoting the social and economic development, and increasing the regional sustainable development capability (Fu et al., 2003).

The concept of ecosystem services, value theory of ecological benefits and assessment methods have gradually been evolved and being used in China since 1990s, with studies on the functions and values of ecosystems, such as the valuation of the importance of ecological functional service (Ouyang et al., 1999; Xiao et al., 2000; Zhang et al., 2001), analysis on the valuation theory and methods of services, functions and economic values of ecosystems (Xu et al., 1999; Zhang et al., 2001); and research on the theory and application of ecological assets division ( $\mathrm{Li}$ et al., 2001). However, the studies on the division of regional ecological functions of fluvial corridor landscapes in arid areas are lacking.

The American Ecologist, Bailey, thought that regionalization is a process to dispart or combine natural

Received 2010-03-08, accepted 2010-04-18

doi: 10.3724/SP.J.1227.2010.00123

* Corresponding author: Huarong ZHOU (E-mail: zhouhr@ms.xjb.ac.cn) 
units according to their spatial distribution. In 1976, he first put forward the concept of ecological regionalization, delineating the regional ecosystems regions of the United States (Bailey, 1976, 1983). Some Chinese scholars (Xiong, 1980; Ni, 1998; Fu et al., 1999, 2001b; Yang, 1999) also did the research on ecological regionalization, and applied it to the agricultural production and the industrial structure adjustment. While it lacks a systematic study on the effect and impact of humans on ecosystem change, the ecological function regionalization emphasizes the differentia of ecosystem functions and is a geographically spatial regionalization based on the differentia regularities on the characteristics of ecosystem, the process and effect of stress, the importance of ecology service function and the sensitivity of ecologic environment. It is an important basic work about environmental protection and rehabilitation following the natural zoning, agricultural planning and ecological regionalization. The eco-function regionalization is the base and a precondition of implementing divisional management of regional environment. In 2002, the provisional regulation of eco-function regionalization was promulgated in China, which regulates the development of eco-function regionalization (Jia et al., 2005).

The ecosystem delineation on the basis of ecosystem services is the geographical identification of resources and the environmental management pursued by China in recent years. It is also the hotspot of geography, ecology and other related subjects from Climate Regionalization in China by Zhu (1931), Plant Regionalization of China by Huang (1940), Integrated Natural Regionalization of China by China Academy of Sciences (1956), and Summarization of Nature Regionalization of China by Chinese Agriculture Regionalization Committee (1984). The geographical regionalization research also got the development from natural comprehensive regionalization and eco-regionalization to the eco-function regionalization, which reflects the cognition advancement of the relationship between human and nature. The major aim of eco-function regionalization is to identify and protect the ecosystems that are important to human welfare, so that these maintain their capability of providing human-needed ecosystem production and services in the long term (Yan et al., 2006).

The Landscape Ecological Regionalization can comprehensively study the landscape heterogeneity and provide more macroscopical cognition for the region. The structure, processes and functions of various ecological regions or ecosystems were deeply understood by comparing and selecting landscape and regional variation analysis. At the application level, landscape ecological regionalization can guide resource and environment management and can frame industry development orientation according to the local conditions.

Unlike other regionalization, the objective of landscape ecological regionalization is landscape ecosystem, which aims to deepen the understanding of the landscape heterogeneity. The ecosystem attribution further requires that the landscape ecological regionalization must be based on the theory of complex systems and hierarchy theory of ecosystem. As a result, the landscape eco-regionalization needs to consider the basic principles of ecosystem integrality, in accordance with the ecological issues of function and landscape ecology at different areas and scales.

Based on the above thought, applying the theory of landscape ecology, the eco-functional regions of the fluvial corridor landscapes in the middle and lower reaches of the Tarim River were divided according to the landscape structure and the ecological functions, and certain measures were brought forward for solving the ecological problems in all of the functional regions. These can provide the theoretical references for rehabilitating the green corridor and controlling the environment degeneration in the lower reaches of the Tarim River.

\section{Study area and methods}

\subsection{Study area}

The study area $\left(38^{\circ} 47^{\prime} 52^{\prime \prime}-41^{\circ} 38^{\prime} 30^{\prime \prime} \mathrm{N}, 85^{\circ} 33^{\prime} 38^{\prime \prime}-\right.$ $88^{\circ} 40^{\prime} 30^{\prime \prime} \mathrm{E}$ ) is dominated by a length of the traditional green corridor from the Kara Reservoir in Yuli County to the Taitema Lake in Ruoqiang County, with a width from the piedmont to the large-area sand dunes. It is $413 \mathrm{~km}$ long and $87 \mathrm{~km}$ wide with an area of 34,526 $\mathrm{km}^{2}$. Considering the integration of landscape ecology and the drainage basin scale of the Tarim River Basin, the study area is a fluvial corridor landscape region with an important ecological function. It covers the alluvial plain, the delta plain in the lower reaches of 
the Tarim River, partial alluvial plain of the Konche River, alluvial plain of the Qarqan River, and the Taklimakan Desert and Kuruk Desert in the south, and the Gobi desert, and fluvial and aeolian-sand landforms. The study area has a warm-temperate arid desert climate and is manly characterized by the distinct four seasons, infrequent occurrence of precipitation and extremely dry air. Strong wind and dust weather, including sandstorm and floating dust, occur frequently in spring. Zonal soil is dominated by brown desert soil. The area of solonchak is large in azonal soil, meadow soil and the aeolian sandy soil distributed in parts of the areas. Because of agricultural development, the core zone of the fluvial corridor is basically occupied by oasis farming areas with irrigation-cultivated soil dominated by fluvo-aquic soil, dominated by fluvo-aquic soil. Zonal desert vegetation is dominant in the study area, and there are also riparian forests of Populus euphratica, lowland meadows and shrubs. The faunal composition is simple. The populations of wild animals are relatively poor. Camelus bactrianus is one of the species of the state first-order protected animals, and Podoces biddulphi is one of the bird species listed in the "World Birds in Severe Danger (1994)", "Global Limited-distribution Birds (1998)" and "Red Book of Asian Birds (2001)".

\subsection{Study methods}

The purpose of landscape ecological planning is to solve the ecological issues at landscape level by using the theory of landscape ecology and to carry out the regulation and optimized designing in favor of the control of the natural components in regional ecological restoration replanning and layout. Regional landscape ecological regionalization is the primary stage and basic work towards the planning for regional landscape ecology and can provide the basis for determining the carrying capacity of regional landscape ecology. On the basis of the above corresponding approaches and regulation measures can be developed for landscape ecological regeneration and designing.

While the landscapes have multiple functions, their structure and functions are accordant. According to the change of the structures, functions and patterns of landscapes, different regions could be planned at different scales and levels. The landscapes being similar in ecological functions, similar approach modes could be taken in the utilization, management and monitor- ing of landscapes. In the study of landscape ecology, planning means the classification of landscape ecological functions, while the divided areas are called the landscape ecological functional areas.

The data for the study, such as the land-use types, soil types, plant communities, their spatial distributions and structures were collected with the help of GIS technology and maps of 1:100,000 Xinjiang Landuse Cartography (Xinjiang Institute of Ecology and Geography), 1:500,000 Soil Type Cartography (Xinjiang Institute of Biology, Pedology and Desert Research) and 1:1,000,000 Xinjiang Grassland Resources Cartography (Xinjiang Animal Husbandry Bureau and Xinjiang Mapping Bureau). On this basis, we carried out field investigations and validation, collected soil samples and related socio-economic statistic yearbooks. Then, we did landscape ecological function regionalization at the drainage basin scale, which is in fact a national scheme of landscape ecological function regionalization.

The natural geographic feature, stress factors, sensitive factor and ecological conservation area have been considered while delineating the landscape eco-functional regions of the middle and lower reaches of the Tarim River, Xinjiang of China. The landscape pattern index (the proportions of patch area, the connection index of patch, etc.), and the existing factors of the spatial distribution of human activities (the administrative districts, agricultural management system, etc.) would be included in bench mark of the delineating of landscape Ecological Function (EF) region.

\section{Dividing principles}

\subsection{Principles of the landscape holistic integrality}

The integrality of landscapes and ecology in the study area revealed that it is dominated by the middle and lower reaches of the Tarim River, the fluvial plain of the Konche River basin and fluvial plain of the middle reaches of the Tarim River that meet each other in Yuli County. The Konche River flows into the oases at the lower reaches of the Tarim River through the Kuta main canal, and the Taitema and the terminal lakes of the lower reaches of the Tarim River, are connected with the Qarqan River basin, which increases the diversity of regenerating the green corridor at the lower reaches of the Tarim River. Because of such connec- 
tion of the ecological landscapes, it is necessary to study the holistic integrality of the fluvial corridor.

\subsection{Principles of the geographic zonal and regional differentiation}

The headspring and development of the fluvial corridor are mainly affected by the physical geographical conditions. Regional differentiation is the first law of geography. Regional topographical structure determines the geographical location and development space of the fluvial corridor. The regionalization and planning of functional areas of the fluvial corridor system are related to its regional differentiation to a great extent. Zonal regulations and intrazonal regulations affect the substratal features and the practical features of the fluvial corridor respectively. In the middle and lower reaches of the Tarim River, the change of inflow from the upper reaches and the shift of the watercourse location play an important role in the regional intrazonal differentiation, especially in the corridor integrality, the change of various type areas and the shift of patches.

\subsection{Principles of the landscape heterogeneity}

Landscape is a natural-human synthesis forming under the effects of human activities (Forman and Godron, 1986). Currently, there is almost no pure natural environment because of human activities. Different ecological landscapes can form in the same natural region because of the different ways of land use. Urban landscape and cropland landscape are the representative human cultural landscapes in the study area. The natural landscapes along the fluvial corridor are improved and changed by human activities, such as irrigation including building canals and afforestation, thus the landscapes are changed into semi-human and human ones.

\subsection{Principles of landscape functions and patterns}

Considering from the holistic situation, fluvial corridor is a landscape with multiple functions. The materialization of various functions of the corridor not only originates from the integrative structure, but also forms the different landscape functional areas. The corridor system is composed of the different interlacing landscape factors including the sub-landscape substrata, patches and corridor which play different ecological landscape roles in the holistic fluvial corridor.
For example, cropland patches play a substratal ecological landscape role in some regions. The corridors, such as highways, canals, forest belts, pipe lines, electric transmission lines and communication lines, play a pivotal role in the regional connection and development of the fluvial corridor. The patches are connected by the sub-corridors to form the extended landscape ecological functional areas of the fluvial corridor.

\subsection{Principles of the fluvial corridor evolution and the cultural landscapes}

Formation and development of the fluvial corridor is a process, and the current pattern of the fluvial corridor is a stage of the whole development process. The current and prospective regional situation of the fluvial corridor is consequentially affected and restricted by its development history. The change of the watercourses in the middle and lower reaches of the Tarim River significantly affects the current pattern of the fluvial corridor. The culture and landscapes of the drainage basin affect obviously the actuality and development of the fluvial corridor and even the distribution and features of landscape ecology. For example, the ancient Loulan civilization, local culture in the Lop Nur Lake region and the reclamation culture of construction corps are all the remarkable historical markers being remained along the fluvial corridor in the middle and lower reaches of the Tarim River.

\subsection{Principles of the carrying capacity of land- scape ecology and its control approach}

Development and features of the fluvial corridor system are undoubtedly affected and restricted by the environmental capacity and the carrying capacity of landscape ecology. The ecological distribution and the landscape pattern along the fluvial corridor in the middle and lower reaches of the Tarim River are significantly affected by the hydrological conditions and the volume of water resources. The development scale and direction of the oasis are certainly restricted by utilization of water resources and its threshold value. Sustainable development of the fluvial corridor should be carried out on the basis of the carrying capacity of landscape ecology and the ecological security. In the division at different levels, the ways and limits of ecological regulation are different. In dividing the type areas, the volume of water resources can be possibly regulated. In dividing subareas, the spatial redistribu- 
tion of water resources can rationally be regulated only by the volume of water resources and landscape features in a region. In following dividing plots, the regulation can be carried out by considering the rational distribution and regulation of ecological utilization ways and the rational distribution of crop species and plant community regeneration.

\section{Landscape ecological function reg- ionalization and its features}

\subsection{Division system of the landscape ecological function areas}

A landscape ecological function area is a hierarchical system of regionalization, and the study area can be divided into 4 levels: the landscape type area, landscape sub-area, landscape plot and landscape factor plot. In this study, the spatial processes of landscape patterns of the landscape type areas are analyzed only, others are only used in the division theory and methods of the functional areas.

Landscape type area: the landscape type area pattern of the first-level division system of landscapes is used as the division index, i.e., the interaction index between the area proportions of landscape types and patches, and the connection features of the fluvial corridor are fully considered, especially the crowding level of wetland and cropland landscapes, and existing factors of the spatial distribution of human activities, including the administrative areas and the agricultural running system. Based on the principles of landscape functional division, as mentioned above, and the distribution map of landscape pattern of the fluvial corridor, the fluvial corridor in the middle and lower reaches of the Tarim River can be divided into three main landscape ecological functional areas (Fig. 1):

(1) Town-oasis agriculture landscape ecological area from the Yuli-Qala Reservoir section to the middle reaches of the Tarim River-Konche River (hereafter referred to as "EF1" area, the same below);

(2) Land-reclamation-cultivation oasis landscape ecological functional area from the Qala Reservoir to the Daxihaizi Reservoir along the upstreammidstream section of lower reaches of the Tarim River (EF2);

(3) Ecological regeneration landscape ecological functional area of the Daxihaizi Reservoir-Taitema
Lake-Ruoqiang from the downstream section of lower reaches of the Tarim River to the lower reaches of the Qarqan River (EF3).

The nomenclative method of the functional areas/region can be expressed as:

$$
T_{a}=A_{f}+A_{s}+F
$$

where, $T_{a}$ is a type area; $A_{f}$ and $A_{s}$ are a section of the fluvial corridor and a subsection of the drainage basin respectively; and $F$ is the landscape function.

Landscape subarea: the features of landscape type patterns of the second-level division system of landscapes are regarded as the division bases in landscape type area, and the heterogeneity of landscape patterns, disturbing degree of human activities, utilization ways and sustainable development prospect are considered. For example, EF1 area can be divided into the farming-oasis-grazing landscape subarea along the downstream section of lower reaches of the Tarim River, Sinear industrial subarea along the National Highway No. 218 (also Kuta main canal), shelter-forest corridor-grassland construction subarea in Yuli County along the National Highway No. 218, Xingping Township-Tarim township farming-oasis sub-area where cotton growing is dominant, town development and ecological garden construction subarea of Yuli County town and its vicinities. EF2 area can be divided into the farm-town zone development subarea, oasis-farming subarea of irrigated area of the Kuta main canal, subarea where the projects of returning land for farming to forestry and grassplot and ecological regeneration are implemented. EF3 area can be divided into the ecological regeneration subarea of the green corridor along the lower reaches of the Tarim River (it can further be divided into the subareas upstream and downstream from Aragan respectively), subarea of natural environment maintenance and historic site protection in the Taitema Lake and Lop Nur Lake regions, and subarea of irrigated area of the Ruoqiang River near Ruoqiang County town and the town-oasis.

Landscape plots: a landscape subarea can be divided into some landscape plots similar to the various functional plots in a county town, such as shopping centers, residential areas and leisure areas. A landscape ecological functional area should be divided 


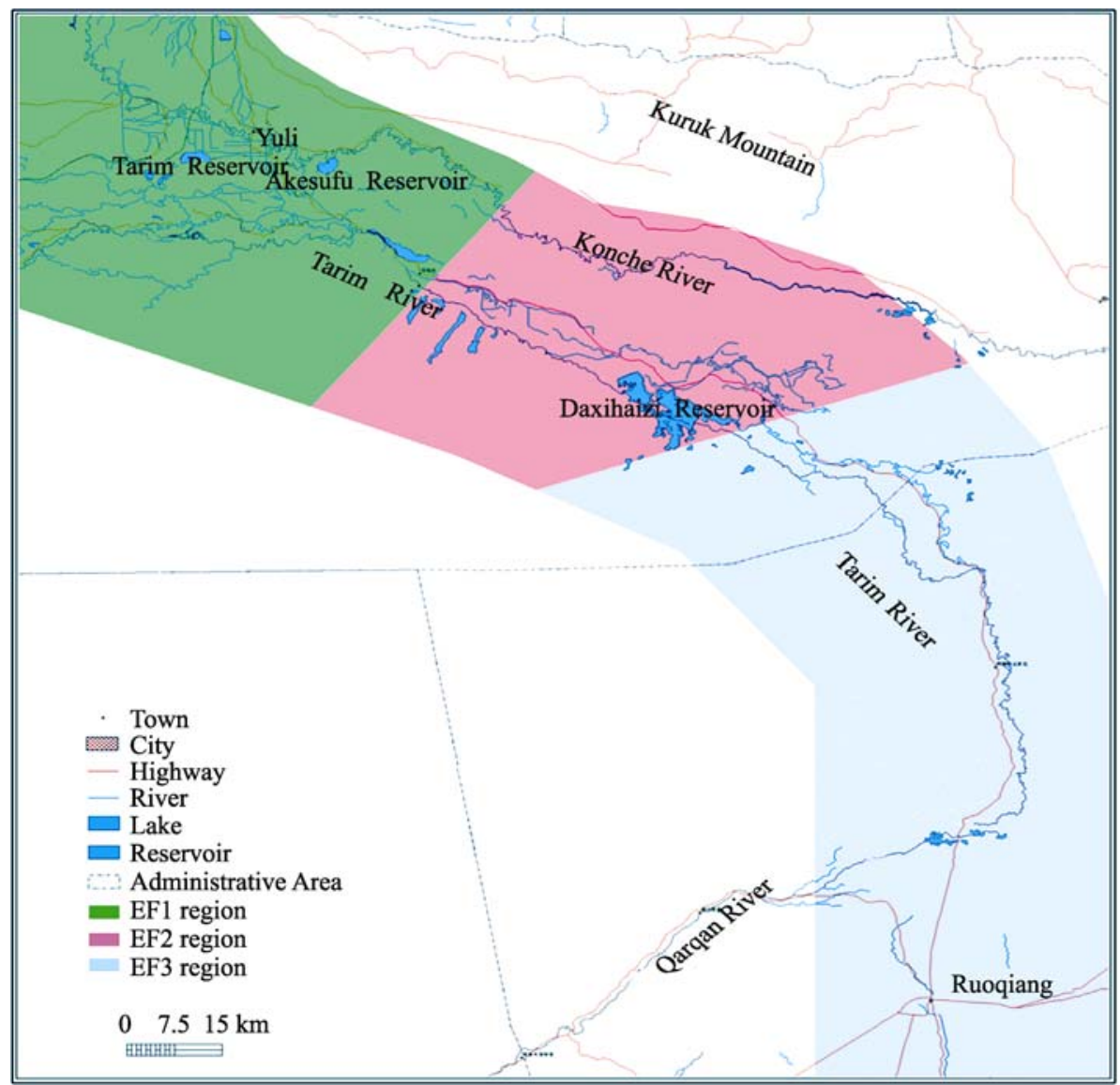

Fig. 1 Map of landscape ecological function regionalization of in the middle and lower reaches of the Tarim River, Xinjiang of China

according to the environmental functions. Moreover, the plots can be connected by corridors, which is different from the general regional division. For example, some leisure area can be connected through certain corridors (roads, forest belts and canals) in arid areas to form grouped and dispersed leisure landscape plots. In the oasis subareas, the landscape ecological functional plots can be divided based on the different crop plots (including the utilization of grasslands and economic-forest garden plots).

Landscape component subplots: actually, a landscape plot can be further divided into some landscape component plots, which belong to the garden landscape design. The landscape component plots are outstanding in urban functional plots, and they can be developed in other landscape functional plots and have great significance in practical application, which is an innovation in researching the scale functions of landscape ecology.

\subsection{Landscape ecological functional area and their features}

(1) Town-oasis-farming landscape ecological functional area of the Yuli-Qala Reservoir section along the middle reaches of the Tarim River-Konche River.

The area covers the downstream section of lower reaches of the Tarim River and partial Konche River basin in Yuli County. Its total area is $985,857.3 \mathrm{hm}^{2}$ and occupies $28.3 \%$ of the studied corridor region. In the studied corridor, there are three main geographical landscape types: (i) The Kuruk middle and low mountainous region and the piedmont pluvial plain are located in the northern marginal zone of the corridor. They are distributed in an east-west slightly-dissected belt along the eastern section of the south Tianshan Mountains, where the gravel Gobi desert landscape is dominant. The desert natural vegetation includes some extra-xerophytic shrubs and semi-shrubs with sparse 
growth, and the vegetation grade is very low if as grazing grassland. The corridor covers partial piedmont pluvial plain only, and the zonal features of the corridor are obvious; (ii) The alluvial-pluvial plains of the Konche River and the Tarim River are main part of the fluvial corridor, where the farming and natural oases are distributed. The woodland landscape and the landscape of natural vegetation with moderate and high coverage are distributed in a concentrative way, and the floodplains forming under watercourse change of the two rivers connect each other. The alluvial plain of the Konche River is narrow but stable and its area is less than a quarter of the whole alluvial-pluvial plain. Large oasis was formed on the alluvial-pluvial plain of the Tarim River because of the frequent shift of the river course and dense ancient river courses. However, some ecological issues, such as the serious desertification, large area of salinized or alkalized lands and sandy lands, grasslands with low vegetation cover, deterioration of environmental quality and poor ecological functions, occured due to the sharp reduction of inflow from the upper reaches of the Tarim River and Konche River; (iii) Kuruk Desert is located in the eastern part of the fluvial corridor, and it is seriously harmful to the fluvial corridor. A serious ecological impact occurred in the functional area and its downstream areas due to the uncontrolled diversion of irrigation water during the period of land reclamation and cultivation.

In this area, compared with the whole fluvial corridor in the middle and lower reaches of the Tarim River, some high-quality landscapes are distributed. Relatively, the areas of woodlands, grasslands, wetlands and farming landscape are large and their proportions are high, whereas the areas of sandy lands, Gobi deserts and salinized or alkalized lands are small and their proportions are low. The landscape functions are relatively stable, but the utilization of water resources and the farming are at extensive stage all along.

(2) Land-reclamation-cultivation oasis landscape ecological functional area along the upstreammidstream section of lower reaches of the Tarim River of Qala Reservoir-Daxihaizi Reservoir.

This area is located along the upstream-midstream section of the lower reaches of the Tarim River, and its total area is $826,728 \mathrm{hm}^{2}$ and occupies $23.94 \%$ of the study area. The Kuruk Desert and Taklimakan Desert are located at its east and south respectively. Stream water of the Konche River is diverted into the Tarim irrigated area through the Kuta main canal and the Katie main canal, and the administrative area ranges Yuli County, which covers 5 farms including the Farm No. 31, 32, 33, 34 and 35 of Second Division, Xinjiang Corps of Production and Construction. The area is surrounded by sand deserts and the oasis. Desert landscapes are alternately distributed. As the ecological nodes and foundations, all the oasis patches play an important role in maintaining the fluvial corridor. They are connected by some artificial corridors, such as the National Highway No. 218, irrigation canals and shelter-forest belts, and these corridors play an active role in maintaining the stability and holistic development of the oasis patches. However, the deforestation for reclaiming land and old-fields in large area resulted in the serious destruction of the regional ecological landscapes during certain period. Because of the rational production and running modes, the construction and management of irrigation works are normative. Utilization of water resources is economical, and the field management is intensive. Quality of the artificial oasis landscapes is relatively high, which affects the area and other landscapes quality. The area of farming landscape is large and its proportion is high However, the area of the grasslands, sparse forests, sandy lands and saline or alkaline lands enlarged significantly and their proportion increased, whereas the area and proportion of wetlands reduced significantly. Moreover, two reservoirs are located in the fluvial corridor at the lower reaches of the Tarim River and play an important role in farming oasis development, but they stimulate the reduction and cutoff flow of the fluvial corridor along the downstream section of lower reaches of the Tarim River.

(3) Landscape ecological functional area of ecological regeneration along the downstream section of lower reaches of the Tarim River and the lower reaches of the Qarqan River of Daxihaizi Reservoir-Taitema Lake-Ruoqiang. 
Ecological break and disappearance of the fluvial corridor along the middle and lower reaches of the Tarim River occurs in this area. The Taklimakan Desert, Kuruk Desert and alluvial plain at the northern piedmont of the Altun Mountain are located at its north, east and south respectively. The area is related to the drainage basins of the Qarqan River, Ruoqiang River and Miran River, and its total area is 1,639,983 $\mathrm{hm}^{2}$, occupying $47.53 \%$ of the study area. The administrative area, at the downstream Yengisu, is under Ruoqiang County and covers Utam township, Tiekanlik township and Ruoqiang Town. The area is related to Washixia township and Farm No. 36 (Miran town) of Second Division, Xinjiang Corps of Production and Construction. The corridor naturally connects with Ruoqiang County town through the Taitema Lake, Qarqan River and Ruoqiang River. After the Daxihaizi Reservoir was built, stream water downstream from it was cut off for more than 20 years, and some ecological problems, such as the dried-up of the Taitema Lake, withering of the forests of Populus euphratica and lowland meadow vegetation, and formation of lands without vegetation, occurred. Currently, the corridor is worthy of its name even more after implementing the projects of rebuilding the National Highway No. 218 and conveying flow water to the lower reaches of the Tarim River for the restoration of the ecology. The areas of the landscapes of Gobi deserts and saline or alkaline lands are the largest and their proportions are the highest, but the area of croplands is extremely small and its proportion is extremely low. In wetland landscape, only some seasonal salty wetlands are distributed. In woodlands, shrubs and sparse forestlands in certain area are distributed. The area of grasslands with low coverage is significantly reduced, and some steppes with moderate and high coverage are also distributed, especially in the regions affected by the Daxihaizi Reservoir and around Ruoqiang County town.

\section{Measures for regenerating landscape ecology in different landscape ecolo- gical functional areas}

\subsection{Landscape ecological regeneration around Yuli County town, a satellite town of Korla City}

The landscape ecological regeneration around Yuli
County town includes the urban construction along the corridor of National Highway No. 218 (including the irrigated areas of the Konche River) and the conservation of Populus euphratica forests along the Tarim River. In urban construction, the establishment of water-saving society, afforestation and beautification of residential environment and environmental carrying capacity should be paid more attention. In order to conserving the forests of Populus euphratica, the value of ecological tourism of the forests and the multiple functions of the landscapes should be fully considered, and the deforestation for reclaiming land must be strictly prohibited. Shelter-forest belts or shelter-grassland belts along roads should be planned and planted based on the local conditions, so they are called the shelter-vegetation belts. These belts can play an important role in reducing wind speed and fixing sand as an ecological function, so such project is called the regeneration of ecological functions in the description above.

\subsection{Landscape ecological regeneration of the oasis farming-ecological conservation-tourism in farms of Xinjiang Corps of Production and Construction}

In this area, the main task of landscape ecological regeneration is the sustainable maintenance and development of the oasis systems (including shelter forests), the predominance of production system and utilizing land and water resources. Therefore, it is suggested to rationally utilize the oasis landscapes including the reservoirs, irrigation canals, croplands, deer farms, sprinkling irrigation systems, develop the cultural landscapes of army wasteland reclamation and cultivation and agricultural tourism. It is also suggested that the steppe landscape in the oasis-desert ecotone should be effectively protected and the area of wasteland reclamation should be strictly restricted to other land uses. Furthermore, optimizing planting structure and increasing crop yield of the existing croplands in the oasis, developing stockbreeding and characteristic livestock (such as deer) breeding in farming areas, testing and demonstrating planting Apocynum venetum are advocated to develop its industry, so as to construct the production bases of organic foods by actively creating favourable conditions. 


\subsection{Landscape ecological regeneration of char- acteristic agriculture-ecological tourism- protection of natural and cultural heritages in Ruoqiang County}

The distinctive contrast between the once brilliance and the current desolation in Ruoqiang County make it more attractive on the contrary. Ecological exploration tour in the county is attractive because of the plentiful historical and cultural heritages (such as the Loulan and Miran ancient cities and the Silk Road) and the particular extremely arid natural landscapes (such as the salt crust, yardang landforms and ancient stream courses). Yingpan and Tuyin in Yuli County and Loulan and Miran are connected in a line to let tourists enjoy the Loulan Ancient City and deeply consider the behavior of human beings in the past. Ziziphus jujuba grown under the peculiar climatic and soil conditions in Ruoqiang County can be regarded as a characteristic primary product, and its development potential is great. Industrial development of halophytes will be started soon, so the experimental study is needed, which is one of the routes to synthetically utilize the halophyte resources. It also has a great development potential. Camelus bactrianus is an animal species which is rarer and more precious than panda in the world. The Lop Nor State Nature Reserve of Camelus bactrianus is located in Ruoqiang County, and the protection of Camelus bactrianus and the habitats is also one of the contents of landscape ecological regeneration in the county.

\section{Discussion and conclusion}

This paper standardized the naming of the landscape ecological areas. As a case of the middle and lower reaches of the Tarim River, the regionalization of landscape ecological functional areas were made. The measures of landscape ecological protection and recovery were presented. It is one of the landscape ecological regionalization studies at the basin level. The quantitative holistic integration analysis of various

\section{References}

Bailey R G. Delineation of ecosystem regions. Environmental Management, 1983, 7(4): 365-373.

Bailey R G. Ecoregions of the United States. Map (scale 1: 7,500,000). data and the establishment of index system were strengthened in this study.

Some scholar have studied the concept of regionalization of special ecological function protection area, which further confirmed the function of ecological service function of landscape ecosystem in regionally ecological stabilization and security (Hao et al., 2007). This concept can guide people to utilize natural resource reasonably, and it is the extendibility of region ecology function zoning. Regionalization of special ecological function protection area is a scope, which has positive or negative effect on region natural ecology stability, society and economy development and people's living standard. It also has one or several dominant landscape ecology types which has a certain special ecological function. The study of regionalization of special ecological function protection area can provide practice case for reasonable layout of economy activities, harmony of environmental relationship and the confirmation of regional ecology restoration and protection aim. The conception approaches the conception of landscape ecology function regionalization.

Landscape ecologic function regionalization is in the same line with ecologic function regionalization and landscape ecology regionalization. At a certain level, they are synonymous. Whereas landscape ecologic function regionalization emphasizes multifunction and landscape scale. Due to the characteristic of heterogeneity and based on matrix-patch-corridor principle, one function district or similar function district departed by corridor can repeat at a lower regionalization level. It is distinguished from ecological regionalization and ecological function regionalization, and it is also an issue in process. This paper researched the landscape ecological function regionalization at a watershed scale and characteristics of zoning division at different levels.

\section{Acknowledgements}

This research was supported by the National Natural Science Foundation of China (40271011).

Ogden, Utah: U. S. Determent of Agriculture, Forest Service. Intermountain Region Press, 1976.

Chinese Agriculture Regionalization Committee. Summarization of 
Nature Regionalization of China. 1984.

Forman R T, Godron M. Landscape Ecology. New York: John Wliey \& Sons, 1986. 64-72.

Fu B J, Chen L D, Liu G H. The objectives, tasks and characteristics of China ecological regionalization. Acta Ecologica Sinica, 1999, 19(5): 591-595.

Fu B J, Chen L D, Ma K M, et al. Theory and Application of Landscape Ecology. Beijing: Science Press, 2001a. 2-3.

Fu B J, Liu G H, Chen L D, et a1. Scheme of ecological regionalization in China. Acta Ecologica Sinica, 2001b, 21(1): 1-6.

Hang B W. Plant regionalization of China. Chinese Journal of History and Geography, 1940, 1(3): 19-30.

Hao R M, Li S Y, Lei J, et al. Study on the zoning of special ecological functional divisions in the urban area of Huhhot City. Arid Zone Research, 2007, 24(50): 624-630.

Jia L Q, Ouyang Z Y, Zhao T Q, et al. The ecological function regionalization of Anhui Province. Acta Ecologica Sinica, 2005, 25(2): 254-260.

Li B. Ecology. Beijing: Higher Education Press, 2000. 197.

Li S C, Zheng D, Yang Q Y. Some issues on assessing natural capital of environment and ecosystems. Journal of Environmental Science, 2001, 22(6): 103-107.

Li Z. G., Wang Y L, Chang H F, et al. Principles and systems of landscape ecological regionalization. Progress in Geography, 2006, 25(5): $10-20$.

Nature Regionalization Committee of China Academy of Science. Integrated Nature Regionalization of China. Beijing: Science Press, 1959.

Ni J, Chen Z X, Dong M, et a1. An ecogeographical regionalization for biodiversity in China. Acta Botany Sinica, 1998, 40(4): 370-382.

Ouyang Z Y, Wang X K, Miao H. A study on the terrestrial ecosystem service functions and economic value in China. Acta Ecologica Sinica, 1999, 19(5): 607-613.

Wang Y A. Study on landscape ecological planning and design in the Weinan region. Journal of Natural Resources, 1995, 10(4): $372-379$.

Wang Y L, Han D. The landscape ecological planning and design of depleted mined land. Acta Ecologica Sinica, 1998, 15(5): 455-462.

Wang Y L. The theory and methods of the landscape ecological division. Journal Applied Ecology, 1996, 7 (suppl.): 121-126.

Xiao D N, Li X Z, Gao J, et al. Landscape Ecology. Beijing: Science Press, 2003. 1-3.

Xiao H, Ouyang Z Y, Zhao J Z, et al. The spatial distribution characteristics and eco-economic value of soil conservation service of ecosystems in Hainan Island by GIS. Acta Ecologica Sinica, 2000, 20(4): $552-558$.

Xiong Y. The importance of ecological regionalization in agricultural modernization. Soil, 1980, (6): 201-203.

Xu Z M, Cheng G D, Wang G. X. A study on the estimation of economic loss from ecological deterioration: a case study in Zhangye Prefecture. Advance in Earth Sciences, 1999, 5(14): 498-504.

Yan N L, Zhao X H, Yu X G. Ecosystem delineation on priority ecosystem services and ecosystem management in the upper Yangtze river. Resources and Environment in the Yangtze Basin, 2006, 15(5): 598-602.

Yang Q Y, Li S C. Some themes on eco-regionalization of China. Acta Ecologica Sinica, 1999, 19(5): 596-601.

Zhang Z Q, Xu Z M, Wang J, et al. Value of the ecosystem services in the Heihe River Basin. Journal of Glaciology and Geocryology, 2001, 4(23): 360-366.

Zhang Z Q, Xu Z. M, Cheng G D. Valuation of ecosystem services and natural capital. Acta Ecologica Sinica, 2001, 21(11): 1918-1926.

Zhou H R, Turson H, Tang P. Division of urban landscape functional districts and its ecological control in Urumqi, Xinjiang, China. Arid Land Geography, 2001, 24(4): 314-320.

Zhu K Z. Climate Regionalization of China. Collected Papers of Chinese Institute of Meteorology. 1931, 1. 